\title{
Letters
}

Website: bmj.com

Email: letters@bmj.com

\section{Legalising active euthanasia and physician assisted suicide}

\section{Assisted suicide is not always as easy as suggested}

EDIToR-Doyal and Doyal argue that there is no difference between assisted suicide, as requested by Diane Pretty, and the withdrawal of life sustaining treatment. ${ }^{1}$ However, there are many complex issues to be considered.

Firstly, how patients come to make an informed autonomous decision must be considered. Many patients with motor neurone disease fear a distressing death, but several studies have shown that this is rare, particularly with good palliative care. ${ }^{2}$ Moreover, assisted suicide is not always as easy and peaceful as is often suggested: a Dutch study reported complications, such as nausea and vomiting, in $7 \%$ of cases, and problems of completion, with longer times to death than expected, in 15\%; doctors intervened and performed euthanasia for $18 \%{ }^{3}$ A decision for assisted suicide can be made clearly and autonomously only if such issues have been fully discussed.

Secondly, the reasons why people ask that their lives should be ended prematurely must be considered. One study suggested that in $80 \%$ of cases the reason is fear of the future (either of a distressing death or of

\section{Advice to authors}

We prefer to receive all responses electronically, sent directly to our website. Processing your letter will be delayed unless it arrives in an electronic form.

We are now posting all direct submissions to our website within 24 hours of receipt and our intention is to post all other electronic submissions there as well. All responses will be eligible for publication in the paper journal.

Responses should be under 400 words and relate to articles published in the preceding month. They should include $\leqslant 5$ references, in the Vancouver style, including one to the BMJ article to which they relate. We welcome illustrations.

Please supply each author's current appointment and full address, and a phone or fax number or email address for the corresponding author. We ask authors to declare any competing interest. Please send a stamped addressed envelope if you would like to know whether your letter has been accepted or rejected.

Letters will be edited and may be shortened.

bmj.com

letters@bmj.com being kept alive), and depression may be responsible for $14 \%$ of cases. ${ }^{4}$ These issues need to be addressed, particularly for a person with motor neurone disease who may have read of the possibility of a distressing death, often from the discussion of cases such as that of Mrs Pretty in the media.

The effects on all involved-the family and close carers, the health and social care professionals, and society itself-must also be considered. Many families find the discussion of assisted suicide difficult, and if complications occur then the memories are far from positive, with family members left with longlasting questions. Many professionals find it difficult to assist in the death of a patient, and one study showed that $24 \%$ of the doctors who had been involved in a case of assisted suicide regretted their decision. These professionals may be left with many questions about their actions.

There is a distinction between the taking of life and the withdrawal of inappropriate treatment to allow life to take its natural course and death to occur. Legalising physician assisted suicide would carry a high risk of undermining the care of all dying patients.

\section{David Oliver medical director}

drdavidoliver@rochester51.freeserve.co.uk

Jackie Fisher consultant physician

Wisdom Hospice, Rochester, Kent ME1 2NU

1 Doyal L, Doyal L. Why active euthanasia and physician assisted suicide should be legalised. BMJ 2001;323:1079-

2 Neudert C, Oliver D, Wasner M, Borasio GD. The course of the terminal phase in patients with amyotrophic lateral sclerosis. J Neurol 2001;248:612-6.

3 Groenewoud JH, van der Heide A, Onwuteaku-Philipsen BD, Willems DL, van der Maas PJ, van der Wall G. Clinical problems with the performance of euthanasia an physician-assisted suicide in the Netherlands. N Engl J Med 2000;342:551-6

4 Zylicz Z, Finlay I. Euthanasia and palliative care: reflection from the Netherlands and the UK. J R Soc Med 1999; 92:370-3.

5 Emanuel EJ, Daniels ER, Fairclough DL, Clarridge BR. The practice of euthanasia and physician-assisted suicide in the United States: adherence to proposed safeguards and effects on physicians. JAMA 1998;280:507-13.

\section{People's autonomy is not absolute}

EDITOR - In their editorial Doyal and Doyal ask, "should she [Diane Pretty, who has motor neurone disease] not be able to invite [her doctors] actively to end her life?"' The right to total personal autonomy is a cornerstone of the pro-euthanasia case, but there is a fundamental problem with this approach. It pictures us as being individual individuals, rather like bricks strewn across a builder's yard, with no relationships, so whatever happens to one brick doesn't affect any others.

We aren't like this. We are more like bricks in a house, where we have close relationships and responsibilities to those around us, friends and family, and we are connected to society as a whole. Our autonomy is balanced by our responsibilities. I don't exert my right to drive to a supermarket at $150 \mathrm{mph}$ because I accept my responsibility not to endanger others.

In his rapid response Fergusson argues that euthanasia is unnecessary, ${ }^{2}$ but suppose that one person still wanted it. For that to happen the law would have to be changed from one that protected everyone's life absolutely to one that left vulnerable people unprotected. In this case the one person ought to waive their right to autonomy because of their responsibility to others.

There is another problem with autonomy: for a choice to be valid it has to be free. Sadly, our society and, sometimes, families don't value old people; they are often made to feel that they are in the way and not useful. Tragically, this is often how the older generation feel about themselves. They know about the NHS's limited resources and may feel guilty about using them up. If euthanasia was legal they would inevitably feel pressured to do the decent thing and die, to stop using up others' resources, be it a hospital bed or the children's inheritance.

Euthanasia is not the answer. Rather, we need to provide meticulous palliative care and by so doing show that people are valued, by our profession and our society.

Malcolm Savage Christian Medical Fellowship staff worker

4 Montgomery Avenue, Nether Edge, Sheffield S7 1NZ

malcolm@savage.fsbusiness.co.uk

1 Doval L, Doyal L. Why active euthanasia and physician assisted suicide should be legalised. BMJ 2001:323:107980. (10 November)

2 Fergusson A. Fancy philosophical footwork but choreography is not coherent. Electronic response to: Why active euthanasia and physician assisted suicide should be legalised. bmj.com 2001. bmj.com/cgi/eletters/323/7321/ 1079\#17410; accessed 26 March 2002.

\section{Seeking this presumed moral good is immoral}

Editor-Doyal and Doyal make a cogent case for legalising assisted suicide, arguing that what is important is the justifiability of the outcome. ${ }^{1}$ Given that death is at times in the best interest of the patient, they assert that bringing about this end is therefore a moral good.

I agree with the authors that the point is not whether death is caused by action or 
inaction. But the difference of intention remains important.

If you decide that it is time to switch off my ventilator and, against all expectation, I continue to breathe spontaneously I hope you would be glad-even if it only delays the inevitable. Your intention was not to kill me: you thought that such extraordinary means were no longer justified in view of what you believed was an unavoidable death.

If I am not in pain yet you inject me with a large dose of diamorphine your intention is to end my life. But suppose that I do have considerable pain and you inject me with a large dose of diamorphine. Here the principle of dual effect is an essential divider: your intention remains the relief of pain, but appropriate intervention is justified even if it also shortens life. When you move on to seeking my death you move also to very different moral ground.

Death may at times constitute a moral good. But how are we to decide? Are we sure that we have the patient's interests at heart and are not influenced by other considerations? Is even the patient able to decide in the emotional turmoil of a serious illness? Even when we believe that death is a moral good, it is a unique one if only for the reason that no one knows what it is like. It is, to borrow a word from the cosmologists, a singularity; and we cannot look beyond it. How are we to weigh the benefits of this unknown entity?

I would suggest that for this unique, sometimes presumed, moral good, uniquely it is immoral to seek it. It may at times be welcomed-even embraced. But we have neither the wisdom nor the moral clarity to use medicine to achieve it.

Andrew G Rivett senior clinical medical officer, communicable disease control

Southampton and South-West Hants Health Authority, Southampton SO16 4GX andrewrivett@sswh-haswestnhs.uk

1 Doyal L, Doyal L. Why active euthanasia and physician assisted suicide should be legalised. BMJ 2001:323:107980. (10 November.)

\section{Strong evidence base must be adduced for euthanasia}

EDITOR-In recent years we have become much more aware that medicine is an inexact science. Up to $10 \%$ of all admissions are associated with an adverse event. Harm is caused to patients as a result of incomplete knowledge, human errors, and system failures.

In a climate of increased accountability and a frank acknowledgement of the limitations of medical science it seems foolish to be promoting the increased use of a treatment as final as euthanasia or assisted suicide without a strong evidence base. An individual case such as that of Mrs Pretty cannot inform the development of legislation, which needs to account for a broad range of scenarios.

The first question that must be answered in a variety of scenarios from teaching hospitals to rural general practice is "how reliable are doctors' predictions of the timing and the inevitability of death?" This may seem burdensome to those eager to start using the "treatment" but is consistent with the rigour applied to all other interventions.

Peter Barratt doctor

Nedlands, Western Australia 6009, Australia peter.barratt@health.wa.gov.au

1 Doyal L, Doyal L. Why active euthanasia and physician assisted suicide should be legalised. $B M J$ 2001;323:107980. (10 November.)

\section{Patients need medical help to live with} dignity until they die naturally

EDITOR-The arguments of Doyal and Doyal rest on an assumption that certain patients are right to want to die and should be killed if they request euthanasia. ${ }^{1}$ This assumption is morally wrong, dangerous, and likely to add to the suffering of vulnerable patients, rather than alleviate it.

I am a full time wheelchair user with spina bifida and also have emphysema and osteoporosis. In addition, my spine is collapsing, causing extreme pain, which is not always controlled even with morphine. These conditions make me the sort of person that the Doyals would consider suitable for "voluntary" euthanasia or physician assisted suicide.

The Doyals would probably say that as they advocate a voluntary system I need not fear being killed without my consent However, there is a problem with this. Some years ago I had a settled wish to die, which lasted many years. Had euthanasia been legal then I would have requested it, and under the current Dutch criteria (often cited as a model to be followed) I would have qualified.

I am alive now only because my friends intervened to save my life on the occasions when I attempted suicide. Over a long period they enabled me to re-establish a sense of my own dignity and worth. Diane Pretty, on the other hand, is surrounded by people who tell her she is right to feel undignified and degraded, and encourage her to fight for a right to be killed.

Even now there are times when my suffering seems too much to bear and I say that I want to die. The Doyals may say I could sign a document saying I want to be kept alive, but of course this could be revoked as long as I remained competent. The fact that I am not terminally ill, as Mrs Pretty is, probably makes my case for being killed even stronger. Mrs Pretty will die soon whatever happens, while I face many years of suffering.

I am terrified of euthanasia being legalised. It would only add to the problems of living with pain that is often unbearable, except that I have to bear it. What I need is medical help to live with dignity until I die naturally. If the Doyals got their way the chances of this happening would recede rather than be advanced.

Alison Davis patient

35 Stileham Bank, Milborne St Andrew, Blandford Forum, Dorset DT11 0LE

alison.davis@talk21.com
1 Doyal L, Doyal L. Why active euthanasia and physician assisted suicide should be legalised. BMJ 2001;323:107980. (10 November.)

\section{Denying people voluntary euthanasia} causes unnecessary suffering

EDITOR-There is plenty of unavoidable suffering. We should welcome an opportunity to mitigate the misery of a lingering death of a person who longs to die. Legalising voluntary euthanasia by a well crafted law would provide such an opportunity. One would think that all reasonable people would agree, and most do, as opinion polls clearly show. But a vociferous minority is intent on raising all possible objections. One of that minority's responses is, "Since 1961 it hasn't been a crime to commit suicide. They can do that."

The case of Diane Pretty illustrates the shallowness of such a response. ${ }^{1}$ Her case undoubtedly has unique features, but I have known many other people near the end of their lives who needed our help to achieve a good death and were denied it.

Five years ago one of my closest friends, also a retired teacher, also with a large family of supportive adult children, spent the summer, from June to September, commit ting suicide. Despite every available medical investigation and treatment nothing had helped her rapid loss of short term memory. She could not read or watch television; by the end of a sentence she had forgotten the beginning of it. It was clear that she was soon going to be able to do nothing for herself, and she decided that such a life was unacceptable.

She persuaded her children that this was the right decision for her. While alone she swallowed all the drugs she could lay hands on, but she recovered consciousness, and so she decided on starvation as the only remaining non-violent means of ending her life. She didn't eat but could not bear the discomfort of doing entirely without water; people dying of physical illness usually die in about 12 days, I believe. She began her abstinence on 22 June and died on 20 September.

Imposing this sort of death on an animal is illegal because it is so cruel. When a person is being denied the right to choose to forego the unacceptable closing phase of his or her life it is much more cruel. Legalising voluntary euthanasia will be one step nearer having a truly civilised society.

Jean Davies retired teacher

56 Marlborough Road, Oxford OX1 4LR jean.davies@dial.pipex.com

**We have permission to publish the details of this case from the family concerned.

1 Doyal L, Doyal L. Why active euthanasia and physician assisted suicide should be legalised. BMJ 2001;323:107980. (10 November.)

\section{Summary of responses}

We received 110 electronic responses and 12 letters to this editorial by Doyal and Doyal arguing for the legalisation of euthanasia and physician assisted suicide. ${ }^{1}$ Fifty six electronic responses were posted 
within a week of the editorial being available on bmj.com and 70 within a week of publication of the printed journal.

Excluding the six published responses above, 30 responses supported euthanasia and physician assisted suicide and 54 were against. The remainder tried to synthesise both sides of the debate, discussed the specifics of the Diane Pretty case, compared the BMA's stance on euthanasia with the arguments in the editorial, and queried why only one side of the debate had been published in the $B M J$ at this time. The sheer volume of the responses and the emotional nature of the debate made it difficult for us to choose which few responses were to be published above and, indeed, which responses are quoted in this summary.

Sri Varman, director of surgery in Cleveland, Queensland, Australia, opened the debate by declaring universal moral bankruptcy: "The system we all have legalises the killing of a 3 month old fetus ... yet denies a woman with an incurable debilitating and fatal illness to die with dignity at the time of her choosing."

Andrew Thornton, a general practitioner in Wiltshire, highlighted how the law is an ass: "A doctor can legally starve or asphyxiate a patient who is on life support but not kill them humanely. The law forbids us to use on humans the humane methods we are allowed to use on animals and would, rightly, prosecute us for starving or asphyxiating a dog." This thread of the debate was taken up by several respondents to bmj.com.

Another thread was euthanasia as an act of commission or omission. Roger Woodruff, a director of palliative care in Melbourne, argued that Doyal and Doyal's "discussion of benefits and burdens smacks of paternalism" and is not relevant to treating terminal illness. Such patients "want care, they want comfort, they want to be allowed to die with dignity; they don't want to be killed. There is a huge difference between allowing terminally ill patients to die, competent or otherwise, and actively killing them."

He ends with talk of the slippery slope, another thread of the debate: "Legalised voluntary euthanasia for the terminally ill leads to involuntary euthanasia, including those not terminally ill, people with treatable psychological disorders, and those who feel a burden. The Dutch have proved this beyond any doubt."

How can we define the direction in which the slope travels, asks Daniel Munday, acting consultant in palliative medicine at a hospice in Warwick. "External reference points, such as the 'sanctity of life', even within the moral maze of clinical practice at least provide us with some hope of knowing where we are. Maybe it is time to re-examine this principle which we have so readily discarded. It might provide a beacon for those of us foundering in 'a sea of relativity.'”

Andrew Warsop, a general practitioner in London, adds: "If human life has some intrinsic value incommensurable with notions of burden and benefit, then death cannot consti- tute a moral good .... If one construes 'care' as meaning the care of the life of one's patient (as opposed to, say, avoidance of suffering) active euthanasia always constitutes a failure in a doctor's duty of care."

Dying people must be protected like other vulnerable groups in society with the provision of pain and palliative care services a core function, argues Paul Keeley, research fellow in palliative medicine in Glasgow. "We need to reassure those in pain that we will not walk away from them. Spiritual and existential suffering is as old as humankinddoctors, it strikes me, are good at treating sickness and physical pain but do not have the skills to try to soothe mankind's deepest fears in the face of death."

$\mathrm{He}$ and other respondents to bmj.com state strongly that doctors should not be called on to do the killing that may be sanctioned by society.

Their point is taken up wryly by Daniel Albert, a general practitioner in Leeds. While agreeing that the arguments of Doyal and Doyal seem logical, he says that they "are frequently put forward by other philosophers....but] far less frequently by practising doctors .... Firstly, it all feels quite wrong. Secondly, our patients might read our articles and wonder if it is they we have in mind.

"And of all professionals, why should it be physicians who get the killing job? The technology is after all simple. The skill will be to assess the meaningfulness of life. Who better than a philosopher to do this?

"The correct phrase is therefore "philosophical killing.' And it would make a good masters degree for graduate philosophers with a practical bent: MA in applied philosophical killing."

Sharon Davies letters editor, BMJ

1 Electronic responses to: Why active euthanasia and physician assisted suicide should be legalised. bmj.com 2001 comj/coi/eletters/323/7321/1079; accessed 26 March 2002 .

\section{Doctors should not decide on medical and "existential" suffering}

EDIToR-The bizarre decision of the Dutch courts that doctors must differentiate between medical and "existential" causes of suffering before agreeing to euthanasia provides an excellent illustration of just why doctors should not get involved with killing people at all. ${ }^{1}$

If society wants euthanasia, fine. Let society draw up the (hopefully) watertight regulatory framework that will prevent abuse of this new freedom, and then let society provide the money for the staff and premises required to provide the service. There will be no shortage of volunteers to train as despatchers (we probably need a better name than that) to work in these new buildings, which I suggest could be known as thanatoria.

There is absolutely no reason why the medical profession should be involved at all, other than to certify that a patient's condition is terminal and that no curative treatment is available. In this way society can have what it professes to want and doctors can preserve their patients' trust by refusing to get involved in the killing.

Bob Bury consultant radiologist

Leeds General Infirmary, Leeds LS1 3EX

bob.bury@doctors.org.uk

1 Sheldon T. "Existential" suffering not a justification for euthanasia. BMJ 2001;323:1384. (15 December.)

\section{Medical education must be rehabilitated in Afghanistan}

EDITOR-Afghanistan needs doctors in rural areas, female doctors, and senior specialists. Female doctors were not trained during the Taliban era and are especially important in a country where cultural norms make it difficult for a doctor to examine a member of the opposite sex. Many senior specialists emigrated over the course of the 23 years of conflict, and those who have remained have been academically isolated for the same period.

Medical education has also suffered. There are four medical schools, in Kabul, Jalalabad, Mazar-I-Sharif, and Herat. The school in Kabul, the Kabul Medical Institute, has continued to produce medical graduates throughout the period of conflict and currently has over 2000 students registered for medical degrees. But the building that houses the institute, a vast Communist era construction in west Kabul, has been severely damaged by the fighting during the 1990s. The building has no functioning plumbing, electricity is available only to a small core facility, $20 \%$ of windows are missing, and classrooms lie empty, looted of furniture, fittings, and equipment.

As a result of the above medical teaching has become entirely lecture based with no facility for laboratory classes. The teaching faculty has been decimated by emigration and weakened by academic isolation. Particular needs are in the fields of anatomy, radiology, anaesthesia, obstetrics and gynaecology, pharmacology, and microbiology, as no Afghan lecturers are currently available, but all departments would welcome outside input and academic links.

For the long term future and development of Afghanistan's healthcare system rehabilitation of medical education must be a priority. This goal can be achieved by the facilitation of academic links with developed world institutions and by considerable investment in the repair of the much damaged building and facilities.

S Mannion honorary lecturer

E Chaloner homorary lecturer

Leonard Cheshire Centre for Conflict Recovery, University College London, London W1N 8AA

F Homayoun country director

HALO Trust Afghanistan, Shari Naw, Kabul, Afghanistan

This report was made on the basis of an exploratory visit to Kabul Medical Institute, which was funded by the United Kingdom based healthcare charity IDEALS. 


\section{National screening programme for diabetic retinopathy}

\section{Digital image may be better for screening}

EDITOR-I work as an ophthalmic photographer, but I have no involvement in screening. Prasad et al assert that screening for diabetic retinopathy by optometrists is superior to photographic screening. This is questionable for several reasons.

Firstly, biomicroscopy detects macular oedema, and more of the retina can be examined. Both are true, but macular oedema will be accompanied by reduced visual acuity, which is easily measured. Treatable retinopathy is most likely to be found around the posterior pole. Is there an obvious advantage in examining the periphery?

Secondly, photography has a high technical failure rate compared with ophthalmology. Careful reading of the paper cited as evidence for this does not give a failure rate for photography of $14 \%$. Of 326 patients, six were ungradable by any means. Twelve of the remaining 320 patients could not be photographed because of posture or tremor. A further 34 patients were ungradeable; 18 of them had opacities preventing photography. True failure rate is not 46 out of $320(14 \%)$ but 16 out of $320(5 \%)$. Prasad et al have added the 12 patients who had posture and tremor difficulties to the 34 who had ungradeable pictures, giving 46 out of 320. Failures were 46 minus 30, equivalent to 16 out of 320 , or $5 \%$. A single technique of examination is not appropriate for all patients, and recording a technical failure when it is impossible for the technique to succeed results in a distortion of the facts.

Thirdly, the choice of digital photography for ease of audit remains valid. Digital photography will improve on the $5 \%$ of technical failures because of instant repeatability.

Fourthly, training will be required for optometrists and technicians. Optometrists are familiar with the slit lamp but will need the skills to examine the fundus with appropriate lenses. How will their competence be assessed and monitored? Training technicians to obtain good quality digital images is less challenging than learning slit lamp biomicroscopy. Validation is easier, and performance can be monitored by the screening centre.

Further advantages of digital imaging should not be overlooked.

Firstly, electronic transmission to remotely located reading centres is practical.

Secondly, the development of automated grading software will make a big difference to the grading workload.

Thirdly, digital imaging presents a valuable opportunity for patient education and motivation.

Optometrists can certainly screen, but a digital image offers important advantages. If obtaining a good image is impossible referral is probably required anyway.

Colin Clements ophthalmic photographer Department of Ophthalmology, King's College Hospital, London SE5 9RS
1 Prasad S, Swindlehurst H, Clearkin LG, Broughton R. National screening programme for diabetic retinopathy. BMJ 2001;323:998. (27 October.)

\section{Screening by retinal photography offers} holistic package of diabetic care

EDITOR-I support the National Screening Committee's recommendation that digital retinal photography is the screening method of choice for diabetic retinopathy. Screening for diabetic eye disease must not be seen in isolation but must be part of the holistic care of patients with diabetes. Evidence shows that diabetic retinopathy can be improved by better diabetic control. ${ }^{2-}$ Patients with diabetes value their eyes; sharing with the patients the photographs that are obtained and explaining the salien features may increase the patients' motivation to be involved in their care.

At Bewdley Medical Centre retinal photographs are kept as part of the patient's diabetic record in the electronic patient record. We share these images with patients, and colleagues and I believe that, though slit lamp biomicroscopy may be the gold standard for diagnosing diabetic retinopathy, it is not the best option for screening diabetic patients. Screening for diabetic eye disease with mydriatic retinal photography has been occurring in our practice and in the Wyre Forest district for the past five years and now covers 108000 patients; our practice of 13700 has 403 diabetic patients.

Our retinal photography programme is cost effective and offers a service that is accessible, clinically viable, and subject to peer evaluation. One of the reasons that retinal photography is considered unacceptable is the quoted risk of "technical failure" of 8.0-14.4\%. ${ }^{5}$ Our experience has been that failure rates are minimal-certainly less than $1 \%$.

We offer a service that does not overburden secondary care. ${ }^{1}$ Our rate of referral to secondary care is low: in 2000, 11 patients were referred, and in 2001, four patients had been referred up until November. We screen for macular oedema with regular, accurate visual acuity assessments.

The retinal photographer is paid $£ 17$ per patient. This includes a quarterly team building and standards meeting and a minimum of four pictures per patient (with additional views of any important or unusual findings). The practice is paid an annual fee of $£ 6041$, giving a total cost of $£ 32$ per patient. We administer the call and recall, report on the retinal photographs, and take necessary action; our secretaries administer our audit, inform each patient of the result of his or her photograph, and add the reports to the diabetic records. We link to a local consultant ophthalmologist, who gives us peer review and helps with difficult management plans.

With the proposed national service framework for diabetes, what must not be lost is the challenge to produce a more patient centred care package for diabetes; mydriatic retinal photography offers us this opportunity.
Clive B Prince general practitioner Bewdley Medical Centre, Bewdley, Worcestershire DY12 2EG

clive.prince@gp-m81057.nhs.uk

1 Freudenstein U, Verne J. A national screening programme for diabetic retinopathy. BMJ 2001;323:4-5. (27 October.)

2 UK Prospective Diabetes Study Group. Tight blood UK Prospective Diabetes Study Group. Tight blood
pressure control and risk of macrovascular and microvaspressure control and risk of macrovascular and microvas-
cular complications in type 2 diabetes: UKPDS $38 . B M J$ cular complications in type 2 diabetes: UKPDS 38. BMJ
1998:317:703-13. [Published erratum appears in BMJ 1998;317:703-13

3 Diabetes Control and Complications Trial Research Diabetes Control and Complications Trial Research
Group. Progression of retinopathy with intensive versus conventional treatment in the diabetes control and complications trial. Ophthalmology 1995;102:647-61.

4 Isotani H, Fukumoto Y. Reversibility of autonomic nerve function in relation to rapid improvement of glycaemic control. Horm Metabol Res 2000;32:115-7.

5 Harding SP, Broadbent DM, Neoh C, White MC, Vora J. Sensitivity and specificity of photography and direct ophthalmoscopy in screening for sight threatening eve disease: the Liverpool diabetic eye study. BMI 1995;311:1131-5.

\section{Authors' reply}

EDITOR-We appreciate the responses of Clements and Prince but believe that their arguments arise from an incomplete understanding of the problem.

Screening aims to detect sight threatening diabetic retinopathy-that is, clinically significant macular oedema with or without proliferative disease requiring treatment or close follow up. Visual acuity is irrelevant in the definition of significant macular oedema. A vision of $6 / 6$ and significant macular oedema are compatible. ${ }^{1}$ Reports by Harding et al (photographic screening) and our team (optometry screening) confirm that measuring visual acuity does not increase the effectiveness of screening. ${ }^{23}$ Photographic screening (without stereopairs) cannot detect retinal thickening. It therefore has to rely on surrogate measures-reduced visual acuity or exudates-and neither is always present in significant macular oedema. Also by definition, the larger the area of retina examined, the better the screening method as the presence of neovascularisation, even peripheral, signifies sight threatening diabetic retinopathy.

Comparing systems, anything not gradable by $\mathrm{A}$, but gradable by $\mathrm{B}$, must be counted as a failure of A. Slit lamp biomicroscopy effectively grades a large proportion of patients with postural or tremor problems or media opacities where photography fails. The essential difference is that biomicroscopy offers dynamic examination, depth perception, and quick interpretation. ${ }^{4}$ This is more likely to cope with difficult situations than is photography, which conspicuously lacks these qualities. Digital photography enables instant recognition of poor images, but it does not always enable the acquisition of acceptable images in difficult situations. Published technical failure rates of photography range from $3.7 \%$ to $34 \%$; we would be very interested in any robust studies showing lower failure rates.

State of the art software for automated detection of diabetic retinopathy detects only microaneurysms, therefore differentiating no retinopathy from any retinopathy. It cannot detect sight threatening diabetic 
retinopathy. Thus, these programmes are at best technology demonstrators' rather than practical answers for today's needs. ${ }^{5}$

Patient education is possible only if skilled reading is available instantaneously, implying that the photographer or doctor interpreting the images has the training to interpret expertly or that instantaneous expert online interpretation is available. The spectre of blindness raised by sight threatening retinopathy is serious, and we would be extremely wary of giving instant reports unless assured that they were valid.

A full cost effectiveness analysis will need to consider all costs, including training, equipment, staff time, etc, and we look forward to such an analysis from Prince's group, rather than just a statement of what is paid to the photographer.

Somdutt Prasad consultant ophthalmologist sprasad@rcsed.ac.uk

Anil Aralikatti fellow in diabetic eye disease Helen Swindlehurst research nurse

Louis G Clearkin consultant ophthalmologis Wirral Hospitals NHS Trust, Wirral CH49 5PE

1 Early Treatment Diabetic Retinopathy Study Research Group. Photocoagulation for diabetic macular edema. ETDRS Report Number 1. Arch Ophthalmol 1985;103:1796-806.

2 Harding SP, Broadbent DM, Neoh C, White MC, Vora J Sensitivity and specificity of photography and direct ophthalmoscopy in screening for sight threatening eye disease: the Liverpool diabetic eye study. 1995;311:1131-5.

3 Prasad S, Jones K, Kamath GG, Phillips RP. Does visual acuity measurement identify uncovered cases when screening for sight-threatening diabetic retinopathy? Ophthalmic Research 1998.30(S1):170. 4 Prasad S, Kamath GG, Jones K, Clearkin LG, Phillips RP:
Effectiveness of optometrist screening for diabetic Effectiveness of optometrist screening for diabetic
retinopathy using slit lamp biomicroscopy. Eye 2001;15 retinopathy using slit lamp biomicroscopy. Eye 2001;15:

5 Prasad S, Jones K and Phillips RP: Telemedicine and computers in diabetic retinopathy screening. $\mathrm{Br} \mathrm{J}$ Ophthalmo 1998;82:851-2.

\section{Infections and risk factors in entrants to Irish prisons}

\section{High prevalence of viral and other sexually transmitted diseases was found in Indian prisons}

EDITOR-Long et al report a high prevalence of viral and other sexually transmitted diseases in Irish prisons and conclude that use of injecting drugs could be the single most important factor for the high infection with hepatitis $\mathrm{C}$ virus there. ${ }^{1}$ They suggest that increased infection control and harm reduction measures are needed in Irish prisons. But they fail to acknowledge other, similar reports, particularly from the countries where HIV infection is highly epidemic.

I and colleagues from the Indian subcontinent conducted a study in 1998 among Indian prisoners. ${ }^{2}$ Altogether 240 male and nine female prison inmates in a district prison near Delhi were screened for sexually transmitted and bloodborne diseases including HIV, syphilis, and hepatitis B and $\mathrm{C}$ viral infections. The inmates were aged 15-50 (mean (SD) $24.8(0.11)$ ). Of the 240 male prisoners, 115 were married and 184 gave a history of penetrative sex. Of the 184, 53 were homosexual or bisexual and the remainder had sex with women only.
Sixty of 131 prisoners were faithful to their partners, while 124 gave a history of having multiple sexual partners and 100 of them had unprotected sex. Eighty three of these 100 had had sex with commercial sex workers. Altogether 126 were addicted to alcohol and 44 to smack/charas; only eight had a history of injecting drug use.

On examination 28 of the 240 had active hepatitis with or without a history of jaundice in the past two years, 25 had active pulmonary tuberculosis, and 11 had syphilitic ulcers on the penis. Four fifths of the teenagers confined to a particular barrack had moderate to severe scabies. Three male prisoners $(1 \%)$ were positive for HIV-1 (confirmed by western blotting) while $28(11 \%)$ male and two (22\%) female prisoners were positive for hepatitis B surface antigen Twelve $(5 \%)$ male but no female prisoners were positive for antibodies to hepatitis $\mathrm{C}$ virus. Of the three HIV positive prisoners, one was an injecting drug user, one was a drug user and frequent commercial sex worker, and the third was homosexual.

This study showed that sexually transmitted and bloodborne infections are highly prevalent in prisons in India and may spread rapidly because of injecting drug use and homosexuality. Interestingly, unlike Long et al we found more hepatitis B than hepatitis $\mathrm{C}$ infection. Injecting drug use was less frequent than in Irish prisons, and homosexuality was probably the most important risk factor in Indian prisons. The study emphasised that more awareness about HIV and hepatitis virus infection is needed in Indian prisons.

Sarman Singh head

Clinical Microbiology Division, All India Institute of Medical Sciences, New Delhi-110029, India ssingh56@hotmail.com Long J, Allwright S, Barry J, Reynolds SR, Thornton L,
Bradley F, et al. Prevalence of antibodies to hepatitis B, hepatitis C, and HIV and risk factors in entrants to Iris prisons: a national cross sectional survey. $B M$ 2001;323:1209-13. (24 November.)

2 Singh S, Prasad R, Mohanty A. High prevalence of sexually transmitted and blood borne infections amongst the inmates of a district prison in north India Int J STD AIDS $1999 \cdot 10: 475-8$

\section{Study in Zambia showed that robust response is needed in prisons}

EdiToR-Long et al's study is yet another reminder that prison health is still a poor cousin of public health outside prison. ${ }^{1}$ In particular, the response to the threat of bloodborne diseases in prisons throughout the world has been slow and at times largely ineffectual.

We have recently concluded a survey of HIV seroprevalence and risk behaviours in Zambian prisons and found the prevalence of HIV to be $27 \%\left(421 / 1566\right.$ inmates). ${ }^{2}$ This finding is much higher than the national average of $19 \%$ but is comparable to the high rates of up to $32 \%$ in the large cities. The main risk factor identified for HIV positive inmates was a history of a sexually transmitted infection

Although we did not find a link between sexual relations between men and HIV infection, we believe that some inmates may be getting infected inside prison. Only $4 \%$ of inmates agreed in one to one interviews that they had sexual relations with other men, but indirect questioning suggested that the true figures were much larger. No condoms were available in any prison.

We did not test our samples for antibodies to hepatitis B and C, but $17 \%$ of inmates had been tattooed in prison and 63\% reported sharing razor blades. The possibility of bloodborne infections in this situation cannot be ruled out. We therefore plan to screen our samples for both hepatitis $\mathrm{B}$ and $\mathrm{C}$ in the next phase of our study. Unlike in Irish prisons, only $4(0.2 \%)$ inmates reported injecting drugs, and this may therefore be a minor risk behaviour for transmission of bloodborne infections in Zambian prisons.

The main thrust of current efforts to prevent HIV transmission in Zambian prisons is still intensive health education. Condoms are not distributed, and conjugal visits are not yet permitted. Health education alone may not be sufficient to stop the spread of HIV, and we propose that more robust and bold policies should be considered, including the use of non-custodial sentences for first time and juvenile offenders. At a time when highly active antiretroviral therapy has become fashionable it is sad that the HIV/AIDS debate in prisons has not progressed.

Oscar Simooya university medical officer

Nawa Sanjobo senior clinical officer

Copperbelt University, PO Box 21692, Kitwe,

Zambia

cbumed@zamnet.zm

1 Long J, Allwright S, Barry J, Reynolds SR, Thornton I Bradley J, et al. Prevalence of antibodies to hepatitis B, hepatitis C, and HIV and risk factors in entrants to Irish prisons: a national cross sectional survey. BMJ 2001;323:1209-13. (24 November.)

2 Simoova OO, Sanjobo N, Kaetano L, Sijumbila G, Munkonze F, Tailoka F, et al. "Behind walls": a study of HIV risk behaviours and seroprevalence in prisons in Zambia. AIDS 2001;15:1741-4

3 Simooya OO, Sanjobo N. "In but free"-an HIV/AIDS intervention in an African prison. Culture Health and Sextality 2001;3:241-51.

\section{Complaints about advertising of medicines are encouraged}

EDITOR-Carvel has given his personal view about advertising by pharmaceutical companies and the code of practice for the pharmaceutical industry of the Association of the British Pharmaceutical Industry. ${ }^{1}$ The code is administered by the Prescription Medicines Code of Practice Authority, at arm's length from the association itself. The code is available from the authority, the association's website (www.abpi.org.uk), its medicines compendium, and the eMC website (www.emc.vhn.net).

The Prescription Medicines Code of Practice Authority supports Carvel's view that those dissatisfied with pharmaceutical advertising should complain to it. Of the 121 complaints made in 2000, 57 came from members of the health professions and 52 from pharmaceutical companies. Intercompany complaints may be seen by Carvel as 
"dog eat dog," but they are an effective control as companies will examine their competitors' promotional material extreme carefully.

Carvel was provided with a detailed response. The relevant companies submitted that the use of the word "urgent" referred to the need for urgent treatment of women at risk of further vertebral fractures. The code of practice panel ruled no breach of the code. The overtly promotional appearance would make it unlikely that recipients would think it had come from an official source. In the panel's view the mailing would not cause offence to most recipients and the promotional nature of the mailing had not been disguised.

With all complaints the unsuccessful party has the right to appeal the panel's decision to the code of practice appeal board, which consists of 19 members including its independent legally qualified chairman, Nicholas Browne. There are six other independent members, three medically qualified, a pharmacist, a member from a body that provides information on medicines, and a member representative of the interests of patients. The other members are from pharmaceutical companies.

The Prescription Medicines Code of Practice Authority is disappointed that Carvel considered that he got nowhere by formally complaining, particularly as by not appealing the panel's ruling of no breach he did not complete the available self regulatory procedure. Even now the procedure is not exhausted as the matter could be reconsidered in the event of a further complaint. The outcomes of all cases considered under the code are published. The relevant report was published in the November 2001 Code of Practice Review. Copies are widely circulated and are available from the Prescription Medicines Code of Practice Authority.

Heather Simmonds director

Prescription Medicines Code of Practice Authority, London SW1A 2DY

hsimmonds@apbi.org.uk

1 Carvel D. A complaint about drug company advertising. BMJ 2001;323:1259. (24 November.)R:IWp-Edit $\backslash P-T O-$ X\Letters-x $\backslash$ simmonh.doc

\section{Declarations for new doctors are unnecessary}

EDITOR-The declaration for new doctors devised by Sritharan et al and shown in their editorial is nonsense. ${ }^{1}$ It is meaningless waffle and unlikely to benefit anyone, and the statement that a professor of medical ethics was involved engenders little confidence.

The stated ideals of the declaration, like those of Christianity, are impossible to attain. The first hurdle comes in the first line: "I will to the best of my ability serve humanity." When in imminent danger of falling from a rockface it is indeed possible for me to hang on to the best of my ability, but it can't be done for very long. Do these authors have no sense of the ridiculous?
Christians counsel against letting the perfect be the enemy of the good, in the sense of making the best use of Christian principles, which are already well known. This is no excuse for the deliberate introduction of a new set of aims that are plainly unachievable from the outset.

The declaration says, "I shall never intentionally do or administer anything to the overall harm of my patients." What about intentionally giving thrombolytic drugs after myocardial infarction? Some of those patients will have strokes, and some of them will not derive any cardiac benefit from the thrombolysis. We know that before we start, but we hope that the numbers come out right in the end. "I shall not do or give anything to my patient with the intent of overall harm" would be better, but such tinkering cannot restore this document to sense.

Do not put your faith in medical ethicists. When you are dealing with real patients in the middle of the night they won't be there; they will be on television affecting to agonise over difficulties while secure in the knowledge that they won't have to deal with them. You will be the one who gives the thrombolysis that gives a patient a stroke or who performs the operation that turns out badly. I suggest that adverse events, culpable or otherwise, will be no less (and, to be fair, no more) likely when the practitioner has made this declaration.

The Hippocratic Oath had the merits of traditional ceremony, which was not expected to mean anything and was rarely used. The credulous are now exhorted to make this silly public declaration for fear of seeming deficient in "caring and sharing" credentials. I urge that this notion is rejected. All you really need to swear to yourself is, "I promise to try reasonably hard to do a reasonably good job." But you have to mean it.

William T Stevenson consultant radiologist, Burnley 6 Flowerfields, Catterall, Preston PR3 1YU wtjs@ouvip.com 1 Sritharan K, Russell G, Fritz Z, Wong D, Rollin M, Dunning
J, et al. Medical oaths and declarations. BMJ 2001; 323:1440-1. (22-29 December.)

\section{Continuity would be achieved with patient held records}

Editor-Krogstad et al write about the subject of continuity of care. ${ }^{1}$ The need to balance division of tasks with coordination of tasks applies as much to primary as to hospital care. Both depend on developing team responsibility, which means including patients as active members of the team.

Obviously patients cannot depend always on one exhausted professional bu should relate to teams small enough for them to form continuing personal relationships. Within teams the only invariable members are the patients. If they are not actually there they must be represented by their narrative medical records, which should be a cumulative, organised story. To ensure that these stories are updated and include relevant social and biological data they must be held by and accessible to the patients.

One measure of continuity is the number of times that people have to repeat their personal stories. This narrative element needs to be separated from necessary but functionally different speculative notes written by doctors and from other clutter attached to records because there is nowhere else to put it. Cumulative objective data (little of which will be comprehensible to patients) can be attached to these core narratives.

Such rationalisation should not be too difficult with computer held records. Over $80 \%$ of NHS general practitioners use computers for patient care, so providing an annually updated personal medical narrative of major events for every registered patient is feasible. Currently it is rarely done, to the despair of conscientious but impotent general practitioners. ${ }^{2}$

To develop such patient held narrative records, though feasible, is not easy. For general practitioners to be approved as trainers nominally means that their medical record systems contain complete summaries of major events. This nominal feature would have to become actual, include major social and clinical events, be extended to all patients in all practices. This would be a huge task, but as good personal care depends on it it cannot be refused and resources must be provided.

This principle of moving towards patient held records was accepted at a policy forum of the Wales Labour party, and a working party to devise steps forward is likely to be set up. ${ }^{3}$ Once narrative patient held records become common at primary care level the rest of the NHS may follow. In 1992 I proposed that health economists and policy formers should take seriously the proposition that patients need help to move away from their status as supplicants or consumers to become coproducers of their health. ${ }^{4}$ Few seem to have done so. Perhaps Wales will lead.

Julian T Hart external professor of primary care policy Welsh Institute for Health and Social Care University of Glamorgan, Pontypridd CF37 1DL jthart@glam.ac.uk

1 Krogstad U, Hofoss D, Hjortdahl P. Continuity of hospital care: beyond the question of personal contact. $B M J$ 2002;324:36-8. (5 January.)

2 Gray DJP. The key to personal care. J R Coll Gen Pract 1979;29:666-78.

3 Labour Party Wales Policy Forum. Proposed amendments to final documents, report 2, Swansea 1-2 December 2001. Cardiff: Wales Labour Party, 2001.

4 Hart JT. Two paths for medical practice. Lancet 1992:340:772-5.

\section{Hospital responsibilities and communication must be clear}

EDITOR-Cawood, a senior house officer, kept a record of the time he spent talking to patients' relatives. ${ }^{1}$ In all complex illnesses, especially those with potential long term sequelae, clinical effectiveness and governance recommend that services are "organ- 
ised." This allows patients the benefit of agreed pathways, with appropriate clear divisions of responsibility and lines of communication between the many different professional and other groups concerned.

The Welsh clinical effectiveness initiative's national demonstration project for implementing clinical effectiveness in acute stroke and the Royal College of Physicians' national clinical guidelines for stroke both identified the need for and benefit of effective dialogue between staff, patients, and carers. This is now being recommended across the specialties.

Infection, difficulty with swallowing, or ignorance of pre-existing comorbidities can undermine excellent surgical and other interventions. In the acute episode many patients are too frail or sleepy to communicate. Relatives can describe patients' faculties before the intervention and interpret statements for staff. Patients can make requests to relatives that they may be too shy to make directly to staff.

An organised service could include this form of dialogue in the clinical pathway, informing patients and relatives before admission of the structures to facilitate communication. Relatives could be asked to nominate a contact person who could be reached by telephone when essential information was needed and who would be responsible for relaying information to and from other relatives.

Ward-based patient liaison officers already facilitate this service in some hospitals. Added benefits include reduced stress for both relatives and staff, and the possibility of including a pre-agreed structure of information that protects confidentiality while meeting clinical and social needs.

Simant Westley public health scientist Department of Health Policy and Public Health, North Wales Health Authority, c/o Institute of Medical and Social Care Research (IMSCAR), University of Wales, Bangor LL57 2UW

Simant.Westley@nwales-ha.wales.nhs.uk

1 Cawood T. Great expectations: a relative dilemma. BMJ 2001;323:1375. (8 December.)

\section{Pattern of some parents' complaints against doctors must be recognised}

EDITOR-The cosignatories to Marcovitch's letter are not the only paediatricians who have been referred to the General Medical Council by parents of children with alleged fabricated illness (Munchausen's syndrome by proxy). ${ }^{1}$ In our department two of five consultants have been referred in similar circumstances. In both cases allegations against the doctors were unsubstantiated.

This abuse of complaints processes needs to be seen in a wider context of an abnormal pattern of behaviour manifested by the parents of these children. Although the behavioural characteristics of such parents has been reported, ${ }^{2}$ the use and abuse of complaints processes is less well recognised.

Associated behaviour that we have witnessed includes repeated requests for copies of medical notes; allegations that the medical notes are incorrect or that pages are missing; requests for changes to be made to medical records so that any references to possible Munchausen's syndrome by proxy and possible fabricated illness are removed; expert knowledge of all aspects of complaints procedures and repeated submission of complaints, with different routes and mechanisms of complaint being used; false allegations against doctors about their behaviour and actions; and involving local media and complaining to other agencies about the competencies of doctors involved.

In some cases complaints are directed against more than one person. In one case that we have been involved with the parent referred three doctors to the General Medical Council and one therapist to the relevant professional body.

Initially presenting doctors with factitiously ill children seems in some cases to become more direct manipulation, with complaints being directed at the doctors. Considerable time and effort is required, by all concerned, to respond to this pattern of behaviour. Recognition of this pattern by those who deal with complaints would greatly help clinicians who have to deal with this particularly difficult and challenging form of child abuse.

R A Smith consultant paediatrician

D W Beverley consultant paediatrician

R J Ball consultant paediatrician

York District Hospital, York YO3 7HE

1 Marcovitch H. GMC must recognise and deal with vexatious complaints fast. $B M J$ 2002;324:167-8. (19 January.)

2 Eminson DM, Postlethwaite RJ. Factitious illness: recognition and management. Arch Dis Child 1992;67:1510-6.

\section{Investigating doctors' performance can cause problems of consent and confidentiality}

EdiTOR-After pilot schemes were carried out in the north west of England health authorities in England established panels to address poor performance among general practitioners. ${ }^{1}$ Through experience several important ethical issues have arisen that need to be addressed by the panels, the National Clinical Assessment Authority, and primary care trusts.

The need for obtaining patients' consent is a major issue. Gaining such consent may be difficult when poor performance is discovered in the absence of the patient-for example, when medical records have been scrutinised by a new doctor. The ability to proceed without the knowledge or consent of the patient needs to be established.

A second issue is whether concerns can be investigated without the patient's identity being disclosed to the doctor. Patterns of unacceptable performance based on the cases of several patients may emerge to a third party-for example, another healthcare worker or the community health council. Permission to approach the doctor may be unknown or withheld. Without substantiated evidence a judicial investigation would have difficulty progressing. Principles of natural justice dictate that people need to know their accuser's identity. But, if this approach is followed rigidly, cases of poor performance will not be investigated and an educational opportunity will be lost.

The final issue relates to promoting the conditions for doctors to acknowledge and remedy their shortcomings. This includes overcoming doctors' natural defensive reaction to their self esteem and removing them from the glare of publicity. This can be achieved by offering confidentiality to doctors undergoing remedial education. This policy would, however, be in sharp conflict with the public's increasing demand for accountability and information on the quality of their health care.

Three publications by the General Medical Council give little recognition to the work of those investigating poor performance. ${ }^{234}$ Guidance from the Department of Health allows information to be passed to a third party on a "need to know" basis for the purposes of "assuring and improving the quality of care and treatment" and "effective healthcare administration."

Both the General Medical Council and the Department of Health acknowledge that the need to protect public safety can override both patients' and doctors' rights to confidentiality. The problem of reconciling the different requirements needed for an educational, or a judicial approach, however, has not been appreciated. The interpretation of current guidance therefore makes the management of poor performance more difficult. These issues need to be resolved as a matter of urgency.

M E Y Capek chair

Manchester Performance Panel, c/o Manchester Health Authority, Manchester M60 7LP

M O Roland director

m.roland@fsl.cpcr.man.ac.uk

National Primary Care Research and Developmen Centre, University of Manchester, Manchester M13 9PL

1 Rotherham G, Martin D, Joesbury H, Mathers N. Measures to assist GPs whose performance gives cause for concern. Sheffield: School of Health and Related Research, University of Sheffield, 1997 .

2 General Medical Council. Confidentiality: protecting and providing information. London: GMC, 2000.

viding information. London: GMC, 2000. Lentical Council. Maintaining good medical practice. London: GMC, 1998

General Medical Council. Management in healthcare: the role of doctors. London: GMC, 1999.

5 Department of Health. The protection and use of patient information: guidance from the Department of Health. London: DoH, 1996.

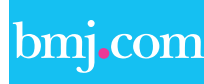

Rapid responses

Correspondence submitted electronically

is available on our website 